\title{
Effect of temperature on the growth of the commercially fished common whelk (Buccinum undatum, L.): a regional analysis within the Irish Sea
}

Emmerson, Jack; Hollyman, P.R.; Bloor, Isobel; Jenkins, Stuart

\section{Fisheries Research}

DOI:

10.1016/j.fishres.2019.105437

Published: 01/03/2020

Peer reviewed version

Cyswllt i'r cyhoeddiad / Link to publication

Dyfyniad o'r fersiwn a gyhoeddwyd / Citation for published version (APA):

Emmerson, J., Hollyman, P. R., Bloor, I., \& Jenkins, S. (2020). Effect of temperature on the growth of the commercially fished common whelk (Buccinum undatum, L.): a regional analysis within the Irish Sea. Fisheries Research, 223, [105437].

https://doi.org/10.1016/j.fishres.2019.105437

\footnotetext{
Hawliau Cyffredinol / General rights

Copyright and moral rights for the publications made accessible in the public portal are retained by the authors and/or other copyright owners and it is a condition of accessing publications that users recognise and abide by the legal requirements associated with these rights.

- Users may download and print one copy of any publication from the public portal for the purpose of private study or research.

- You may not further distribute the material or use it for any profit-making activity or commercial gain

- You may freely distribute the URL identifying the publication in the public portal?
}

Take down policy

If you believe that this document breaches copyright please contact us providing details, and we will remove access to the work immediately and investigate your claim. 


\author{
1 Journal: Fisheries Research \\ 3 Title: \\ 4 Effect of temperature on the growth of the commercially fished common whelk (Buccinum undatum, \\ 5 L.): a regional analysis within the Irish Sea.

\section{Authors:} \\ 10 Address: \\ 11 School of Ocean Sciences, Bangor University, Askew Street, Menai Bridge, Anglesey, LL59 5AB, UK. \\ 12 British Antarctic Survey, High Cross, Madingley Road, Cambridge, CB3 OET, UK \\ 14 Email: j.emmerson@bangor.ac.uk \\ 15 Keywords: commercial fishery, statolith, age, stock assessment, mollusc, gastropod, conservation
}

\title{
Abstract
}

18 In response to increased demand in Asian markets, the commercial fishery for the common whelk 19 (Buccinum undatum, L.) has expanded in north-eastern Europe. In the Irish Sea region (ICES Area 20 20 VIIa), increased effort and landings have raised concerns about long-term stability of the fishery 21 amongst stakeholders. Fisheries in Welsh waters and the Isle of Man territorial sea are now subject to 22 an increased minimum landing size according to the best available scientific data. This study addresses 23 key knowledge gaps by investigating the size-at-age relationship of the species across the latitudinal 24 extent of the fisheries management region. Our findings show that growth parameters, modelled using growth rings observed in the statolith, vary between populations and show a broadly latitudinal pattern.

26 Thermal-time (expressed as sea bottom temperature degree-days) showed a significant negative linear relationship with the asymptotic size reach by whelk populations $\left(\mathrm{L}_{\infty}\right)$, where whelk grew to a larger maximum size in cooler waters. Other parameters, including maximum growth rates and the age at which growth rate begins to decrease, showed clear trends with sea-bottom temperature but linear modelling failed to detect significant relationships, where warmer waters increase the rate of growth in

31 the early life stages of whelk but cooler waters allow growth to continue until later in life. Whilst there 32 are substantial requirements to further validate and refine the relationship between growth and sea33 bottom temperature, extrapolation of these data to other regions in Northeast Europe may provide a 
valuable tool in approximating important life-history characteristics in stock assessments, such as $\mathrm{L}_{\infty}$, age-at- $\mathrm{L}_{50}$ and age-at-recruitment.

\subsection{Introduction}

The common whelk (Buccinum undatum, Linnaeus, 1758) is a neo-gastropod mollusc that is found in the subtidal waters of the North Atlantic to depths of $1400 \mathrm{~m}$ (Mercier \& Hamel, 2008). The species is widely distributed on the Atlantic continental shelf and is frequently found in densities that support commercial fisheries in both Europe and America (Emmerson, et al., 2018; Borsetti, et al., 2018). A small scale fishery has existed in Europe for over a century, with recorded annual landings in England and Wales of $4500 \mathrm{t}$ in 1911 (Dakin, 1912). European waters are the principal area of production (FAO, 2017) and the fishery has undergone significant economic and geographical expansion in response to emerging Asian markets, with global landings increasing from $7000 \mathrm{t} \mathrm{yr}^{-1}$ to over $35000 \mathrm{t} \mathrm{yr}^{-1}$ between 1990 and 2014 (FAO, 2017).

Whelk are the $6^{\text {th }}$ most economically important shellfish species in the UK, with total UK landings (20,800 t) equating to a value of $£ 22.7$ million in 2017 (MMO, 2018). What was once a small-scale inshore fishery is now characterised by a fleet increasing in average length and fishing capacity. For UK vessels under $12 \mathrm{~m}$ in length, whelk has overtaken crab and lobster as the most important shellfish species by volume caught in the 'pot and trap' sector (Lawrence, et al., 2017). For larger vessels (> 12 m) they now rank as the second most important by volume. The same data highlight that over the last decade, the economic significance of whelk has also increased. Among the five most valuable species from 2008 to 2017 in the '10-12 m pots \& traps' sector, catch data shows the relative economic contribution of whelk increase by $10 \%$, whereas, European lobster and edible crab value increased merely by $5 \%$ and Nephrops decreased by half (SEAFISH Economics, 2018). Regionally, the Irish Sea (ICES Area VIIa) has an estimated 447\% increase in the total landed weight of whelk between 2000 and 2016 by British registered vessels, with the most significant increases being recorded in the Isle of Man territorial sea (ICES rectangle 37E5) and Welsh waters (ICES rectangles 33E5, 34E5, 35E5)

61 (Emmerson, et al., 2018). In the Irish Sea, whelk are the third most valuable shellfish resource after 
63 total value of all species landed by UK vessels in ICES VIIa) (MMO, 2018). The value of whelks

64 landed into Wales by UK vessels was greater than all other species combined in 2017 (MMO, 2018).

65

The sustainability of whelk fisheries has been questioned by both fisheries scientists and industry stakeholders (see Nicholson \& Evans, 1997; McIntyre et al., 2015). It is clear, for example, that the widely adopted EU minimum landing size (MLS) (45 mm total shell length; TSL) fails to protect juvenile individuals (individuals below the size of functional maturity; $\mathrm{L}_{50}$ ) from harvest in many regions of the British Isles (Shelmerdine, et al., 2007; Haig, et al., 2015; Emmerson, et al., 2018). The uncertainty, knowledge gaps and localised variation in basic biological parameters such as maturity (Haig, et al., 2015; McIntyre, et al., 2015), fecundity (Valentinsson, 2002) and mortality (Laptikhovsky, et al., 2016), combined with low resolution data on fishing effort and catch has meant that a conceptual framework for stock assessments has not yet been developed. As a consequence, the fishery is considered 'data-poor' and there are no biologically referrenced catch or effort restrictions.

Fisheries management responses to apparent whelk population declines have therefore been precautionary in approach when compared to management decisions for other commercially important species (Fahy et al., 2000; Fahy et al., 2005; Shrives et al., 2015).

An understanding of size-at-age and longevity of exploited marine species are fundamental in most stock assessment models. For effective fisheries management to take place, scientists must be able to understand changes of stock size and structure in response to dynamic anthropogenic (primarily fishing mortality) and environmental factors (Hilborn \& Walters, 1992). Using a size-at-age relationship to estimate parameters such as age-at-recruitment and age-at-first-spawning are especially valuable for evaluating existing management measures that are typically defined using size based metrics, as in the case of whelk fisheries. Modelling the growth parameters of a marine species allows scientists, managers and industry to formulate informed harvesting strategies with a medium-to-long term perspective.

A reliable assessment of age and longevity in whelk populations is problematic for fisheries scientists (Hollyman, et al., 2017b), primarily due to the heterogeneity between populations even over small spatial scales (Shelmerdine, et al., 2007; Haig, et al., 2015). Age determination of this species and other marine gastropods has typically been estimated by counting the growth rings on the operculum, 
an organic 'shield' on the posterior edge of the animals foot (Santarelli \& Gros, 1985). However, issues

of precision, accuracy and reliability (see Kideys, 1996) has meant that the methodology is viewed as suboptimal, with $<20 \%$ of samples displaying clear readable rings (Hollyman, 2017a). Novel techniques examining the statolith, which are an accretory calcareous particle typically $<300 \mu \mathrm{m}$ and integral to the animals central nervous system, have been developed to assess age and growth of gastropod molluscs (Barroso, et al., 2005; Chatzinikolaou \& Richardson, 2007). This has led to a significantly improved degree of accuracy, precision and reliability in determining the age and growth parameters of whelk (Hollyman, et al., 2018). Observing annual periodicity of growth rings in the statoliths of whelk has also been validated using controlled laboratory tank-rearing experiments (Hollyman, et al., 2018a) and by direct chemical analysis of the calcium carbonate structures themselves (Hollyman, et al., 2017b). Angilletta Jr., et al., 2002), including aspects such as locomotion (Bennett, 1980; Young, et al., 2006), sensory input (Werner, 1976), and rates of feeding and growth (Navaro \& Iglesias, 1995). Hollyman (2017a) observed clear variation in growth rates and seasonality of growth in whelk across the British

111 theoretical average maximum size of the sampled population) and whelk in cooler waters to the north

112 were hypothesised to have a greater time-window within which shell growth could occur, maximising

$113 \mathrm{~L}_{\infty}$ values. Variable growth rates were highlighted by Haig et al. (2015) as a potential key driver in 114 localised variation in size-at-maturity $\left(\mathrm{L}_{50}\right)$ and size-structure of whelk populations sampled in South 115 Wales. Haig et al. (2015) also hypothesised that these observations were likely a consequence of local 116 temperature regimes. Whelk experience a large range of sea temperatures across the geographical range 117 of the species $\left(0-22{ }^{\circ} \mathrm{C}\right.$; Smith, et al., 2013). Physiological processes are bound by critical thermal 118 limits, beyond which the processes cease, defined as the critical minimum $\left(\mathrm{CT}_{\min }\right)$ and critical 119 maximum $\left(\mathrm{CT}_{\max }\right) T_{b}$ that permit performance (Angilletta Jr., et al., 2002). The thermal performance 120 curve of whelk is not known but typically may be asymmetric with maximum performance of 121 individuals occurring at some intermediate temperatures (Angilletta Jr., et al., 2002), otherwise known as a thermal preferendum (Sharpe \& DeMichele, 1977). 
Degree-days are an increasingly popular method for explaining variation in growth and development of marine organisms (Chezik, et al., 2014), despite only accounting for 5\% of all temperature related growth studies between 1980 and 2006 (Neuheimer \& Taggart, 2007). Neuheimer and Taggart (2007) found strong linear functions of the DD metric can explain $>92 \%$ of the variation in size-at-age data

128 among forty-one data sets representing species from a variety of marine and freshwater environments 129 as well as laboratory studies. Since the metabolic functioning of whelk, a boreal species, is expected to 130 decrease linearly from a thermal preferendum, we model temperature as a function of DD (Sharpe \& 131 DeMichele, 1977; Angilletta Jr., et al., 2002).

133 This study presents a regional analysis of data from statolith samples collected in the Irish Sea, 134 specifically from within Welsh waters and the Isle of Man territorial sea. Spatial comparisons of the size-at-age relationships are coupled with satellite-derived sea-bottom temperature data in an attempt to

136 empirically explain the relationship between temperature and growth parameters for this geographical 137 area.

\subsection{Materials and methods}

\section{$140 \quad 2.1$ Biological samples}

141 Whelk were collected by industry participants from exploited fishing grounds in both the Isle of Man 142 territorial sea and Welsh waters (Figure 1) using industry-standard Fish-tec ${ }^{\mathfrak{}}$ pots (see Emmerson et al., 1432018 for details). Samples were collected in the Isle of Man during autumn 2016, whilst samples in 144 Wales were collected through 2016 to spring 2017. The whelks were not 'graded' according to MLS to 145 ensure that the maximum range of size classes were available for analysis. They were stored in 146 freezers at $-20^{\circ} \mathrm{C}$ upon landing. Precise spatial details of the sampling locations are not presented in 147 agreement with the participants' requests to protect commercially sensitive data. After thawing, the 148 TSL of each whelk was measured to the nearest $0.1 \mathrm{~mm}$ using Vernier callipers.

$149<$ Figure 1>

150 Figure 1. A map of the Irish Sea showing the general locations where whelk (Buccinum undatum) were sampled. A 151 = Isle of Man, B = Amwlch, C = Nefyn, D = Bardsey Island, E = Carmarthen Bay and F = Swansea Bay. 
154 One statolith from each specimen was extracted using the methodology described by Hollyman, et al.

155 (2018a). The statoliths were mounted onto separate microscope slides using CrystalbondTM 509

156 thermoplastic resin and imaged under a Meiji Techno MT8100 microscope with a Lumenera Infinity 3

157 microscope camera at 20x magnification. Extracted statoliths were visually assessed according to the

158 rankings described by Hollyman et al. (2018) (see figure 3 in Hollyman et al. (2018) for a visual

159 comparison of the quality and clarity rankings of statolith rings; StR) and only specimens ranked 3 or 4

160 were used for subsequent analysis. Photomicrographs were analysed using ImageJ v1.48 (Ferreira \&

161 Rasband, 2012) to count and measure the width of each statolith ring (StR) starting with the hatching

162 ring (Figure 2). After initial training by $\mathrm{PH}$, the agreement in age determination by StR between the

163 two readers was $89.2 \%$.

$164<$ Figure 2>

165 Figure 2. An example of a photomicrograph of a statolith (sampled in the Isle of Man territorial sea, June 2016).

166 Red lines indicate the growth rings observed, with the centremost arrow showing the hatching ring. The blue arrow

167 at the extremity of the statolith structure shows the edge of the statolith and is not counted as an annual growth 168 ring.

\subsection{Temperature data}

172 Sea bottom temperature (SBT) data for each sampling location were extracted from the Global Ocean

173 Physics Reanalysis Products "GLOBAL-REANALYSIS-PHY-001-030", which was acquired through

174 the Copernicus Marine Environmental Monitoring Service (CMEMS) (http://copernicus.eu).

176 The data provides global ocean eddy-resolving ( $1 / 12^{\circ}$ horizontal resolution and 50 vertical levels)

177 reanalysis covering the altimetry era 1993-2016. It is based largely on the current real-time global

178 forecasting CMEMS system. Observations are assimilated by means of a reduced-order Kalman filter.

179 Along track altimeter data (Sea Level Anomaly), satellite Sea Surface Temperature, Sea Ice

180 Concentration and in situ temperature and salinity vertical profiles are jointly assimilated. The global

181 ocean output files are displayed on a standard regular grid at $1 / 12^{\circ}$ (approximatively $8 \mathrm{~km}$ ), with the

182 most relevant grid square to the sampling location being extracted from the overall time series.

184 The annual sum of degree-days (with a base temperature, $T_{0}$, near to the minimum temperature in the 185 coldest extremes of the species; B. undatum: $0{ }^{\circ} \mathrm{C}$ ) can be used to explore the relationship between 
physiological processes and temperature. Degree-days are an expression of thermal-time (Chezik, et al., 2014) or thermal opportunity for growth (Chezik, et al., 2015), where the degree-day for a single day

188 (DD; ${ }^{\circ} \mathrm{C} \cdot$ days $)$ is expressed as:

$$
D D=\frac{\left(T_{M a x}+T_{M i n}\right)}{2}-T_{0}
$$

191 Data were filtered to include SBT for the period 2010-2016. The time series of daily mean SBT data

192 for each location were then calculated as Annual Degree-Days $\left({ }^{\circ} \mathrm{C}\right)(\mathrm{aDD})$ (equation 2$)$. The number of 193 measurements for each region were equal.

$$
a D D=\frac{\sum D D}{\text { time }_{\text {years }}}
$$

\subsection{Modelling growth and $\mathrm{L}_{\infty}$}

TSL-at-age data of each specimen was calculated using a formula calculated by Hollyman (2017a, p.

198 183), which estimates $y$ (size TSL; mm) to be a function of $x$ (statolith width; $\mu \mathrm{m}$ ) such that:

$$
y=43.439 x^{0.4259}\left(R^{2}=0.96, n=1719\right)
$$

200 The measurements from each ring within each statolith sample were then modelled using equation 3 to

201 create an account of growth for each individual whelk. These data were analysed by location and modelled using equation 4 to estimate the average size at each age (ring) within the sampled

203 populations.

205 This pre-analytical calculation was necessary to fill data gaps brought about by difficulties in sampling small whelks under the $45 \mathrm{~mm}$ MLS, so that growth curves could be modelled with a greater goodness-

207 of-fit to size-at-age data. Importantly, this technique avoided the unrealistic application of TSL $\leq 0 \mathrm{~mm}$

208 at age $\mathrm{t}_{0}$ (hatching), which would result in incorrect asymptotic estimates (Hollyman, et al., 2018).

210 Using R (R Core Team, 2017), the size and age data for each observation were modelled using a non-

211 linear least squares regression model fitted with a gompertz growth curve (Tjørve \& Tjørve, 2017), 
212 which captures the sigmoidal relationship of growth in Buccinum and other marine gastropods more

213 than other models (see (Hollyman, 2017a), whereby:

$$
T S L_{t}=L_{\infty} e^{-e^{-k_{G}\left(t-T_{i}\right)}}
$$

$215 \mathrm{TSL}_{t}$ is the size of a whelk shell at time $t, \mathrm{~L}_{\infty}$ is the theoretical average maximum size of the sampled

216 population, $k_{\mathrm{G}}$ is the growth-rate coefficient (which affects the slope), and $T_{i}$ represents time at 217 inflection of growth (i.e. where the curve is orientated against the x-axis, or when growth begins to 218 slow).

220 The estimated coefficient value of $\mathrm{L}_{\infty}, k_{G}$ and $T_{i}$ for each sampled population was then plotted against 221 aDD for each location. Further, aDD was also modelled against maturity $\left(\mathrm{L}_{50}\right)$ estimates taken from 222 existing literature (Haig et al., 2015; Hollyman, unpublished data; Emmerson et al., 2018). The 223 relationship between estimated coefficients and aDD were tested using linear regression to assess 224 whether any significant linear relationship exists.

\subsection{Results}

227 A total of 1,796 individual statoliths were examined (2,973 ring observations) with a size range from $22825.9 \mathrm{~mm}$ to $109.4 \mathrm{~mm}$ TSL across six locations (figure 3). The oldest whelk sampled had 8 clear 229 growth rings (excluding the hatching ring).

\section{$230<$ Figure $3>$}

Figure 3. Size-frequency histograms of whelk (Buccinum undatum) sampled at Amwlch ( $\mathrm{n}=287$ ), Bardesy Island $(\mathrm{n}=279)$, Isle of Man (IOM) $(\mathrm{n}=185)$, Nefyn $(\mathrm{n}=278)$, Saundersfoot (Carmarthen Bay) $(\mathrm{n}=278)$ and Swansea Bay $(\mathrm{n}=304)$.

236 The pattern of growth of whelks differed significantly by location (figure 4, table 1). $\mathrm{L}_{\infty}$ ranged 237 between $59.9 \mathrm{~mm}$ in Swansea and $116.8 \mathrm{~mm}$ in Isle of Man samples. The variation in $\mathrm{L}_{\infty}$ follows a 238 broadly latitudinal trend, with the larger maximum size of whelk being observed in samples in the 239 northern Irish Sea. In contrast, the growth rate $k_{G}$ decreased with increasing latitude, meaning that 240 whelks in the south grew at a faster rate $(\max =1.04$, Carmarthen Bay) than in the north $(\min =0.44$, 241 Isle of Man). 
Figure 4. The modelled size-at-age relationship of Buccinum undatum by sample site in Welsh waters and the Isle of Man territorial sea. Points represent mean TSL at Age \pm S.E.

\section{$246<$ Table $1>$}

248 The satellite data show clear seasonal variability in temperature at each location (figure 5). The lowest 249 minimum temperature was in the Isle of Man $\left(5.8^{\circ} \mathrm{C}\right)$ and highest minimum temperature in Carmarthen 250 Bay $\left(6.9^{\circ} \mathrm{C}\right)$. The lowest maximum temperature was also recorded in the Isle of Man $\left(16.5^{\circ} \mathrm{C}\right)$, whilst 251 the highest maximum temperature was in Swansea Bay $\left(18.4^{\circ} \mathrm{C}\right.$ ) between $2010-2016$ (figure 5).

\section{$<$ Figure 5 $>$}

Figure 5. The daily sea-bottom-temperature $\left(\mathrm{SBT}^{\circ} \mathrm{C}\right)$ at each location sampled for whelk in the Irish Sea for the period 2010-2016.

The average aDD for each location varied between 4004 (Isle of Man, coolest) and 4267 (Swansea Bay, warmest). This equates to an average daily difference of $0.72{ }^{\circ} \mathrm{C}$ between the warmest and coolest locations.

When the size-at-age parameters are plotted against the average aDD value for each location, there are clear negative trends in the data for all parameters with the exception of $k_{G}$ which is positive (figure 6). Linear regression analysis shows a significant effect of $\mathrm{aDD}$ on $\mathrm{L}_{\infty}\left(\mathrm{R}^{2}=0.72, \mathrm{p}\right.$-value $\left.=0.03\right)$ and is described by equation 5a. Linear regression was unable to model the effect of aDD on other growth variables to the same statistical certainty, where $\mathrm{p}=0.07$ for $K_{G}$ and $T_{i}$ and $\mathrm{p}=0.11$ for $L_{50}$. Extrapolating the significant linear model of $\mathrm{L}_{\infty}$ over the aDD data available presents a graphical display of the estimated maximum TSL for whelk populations in the Irish Sea (figure 7).

5a) $L_{\infty}=696-0.15 a D D ; \mathrm{R}^{2}=0.72, \mathrm{p}=0.03 *$

5b) $L_{50}=317-0.06 a D D ; \mathrm{R}^{2}=0.63, \mathrm{p}=0.11$

5c) $K_{G}=-5.7+0.002 a D D ; \mathrm{R}^{2}=0.60, \mathrm{p}=0.07$

5d) $T_{i}=21.7-0.001 a D D ; \mathrm{R}^{2}=0.59, \mathrm{p}=0.07$ 
$<$ Figure 6>

Figure 6. Scatterplots showing the relationship between estimated $\mathrm{L}_{\infty}$, Growth rate $\left(k_{G}\right)$, Age at Gompertz inflection $\left(T_{i}\right.$; years) and functional maturity $\left(\mathrm{L}_{50}\right)$ of whelk (Buccinum undatum) and sea-bottom-temperature (SBT) expressed as annual average degree-days (aDD) in the Irish Sea. The black lines represent the linearly modelled relationships (equation $5 \mathrm{a}-5 \mathrm{~d}$ ) while the grey area shows the standard error in the model. Error bars around the point show the standard error in the parameter estimations. N.B no maturity data is available for Carmarthen Bay samples.

$<$ Figure $7>$

Figure 7. The $\mathrm{aDD} \sim \mathrm{L}_{\infty}$ relationship for whelk, Buccinum undatum, extrapolated throughout the data range of average annual sea bottom temperature (2010-2016) for ICES Area VIIa.

Using growth rings observed in statoliths, the size-at-age relationship was modelled for whelk populations in the Isle of Man territorial sea and Welsh waters using specimens harvested by commercial fishers on exploited fishing grounds. The modelled growth parameters varied by location, with a clear latitudinal trend of increasing asymptotic size with latitude in the Irish Sea. The largest potential size (on average) of whelk populations varied from a maximum of $116.8 \mathrm{~mm}$ TSL (Isle of Man) in the north to $59.9 \mathrm{~mm}$ TSL (Swansea Bay) in the south, a pattern analogous with observations by Hollyman, et al. (2018) where samples were taken across a geographic range from Shetland to Jersey. This pattern is also observed in the size-distribution data for Irish Sea whelk presented in

300 Emmerson et al. (2018). Whilst we observe large variation in size and growth of whelk over latitudinal 301 scales, similar levels of variation have been observed in size-at-maturity and population structure at 302 local levels, suggesting the growth of whelk may vary significantly over local scales (Haig et al., 2015).

303 Studies examining the life history of this species have consistently alluded to or hypothesised that sea304 bottom temperature is the fundamental environmental driver of variation (see Bell \& Walker, 1998; 305 McIntyre et al., 2015; Hollyman, et al, 2018). This study is the first to test the relationship between 306 growth parameters and SBT using observed data from statoliths sampled throughout the latitudinal 307 extent of a fisheries management area together with SBT derived from modelled satellite data. 
309 A significant negative linear relationship between temperature, expressed as aDD, and $\mathrm{L}_{\infty}$ was found

310 for the species on a regional scale in the Irish Sea (ICES Area VIIa), where the average maximum size

311 of an individual within a population decreases with increasing average annual sea-bottom temperature.

312 The Swansea Bay area experienced the greatest aDD of 4267 between 2010 and 2015 with populations

313 showing $\mathrm{L}_{\infty}$ of $59.9 \mathrm{~mm}$ TSL. Cooler waters in North Wales around the Llyn peninsula $(\mathrm{aDD}=4174)$

314 and Anglesey $(\mathrm{aDD}=4017)$ meant whelk there reached a larger $\mathrm{L}_{\infty}, 89.6 \mathrm{~mm}$ and $90.9 \mathrm{~mm}$ TSL

315 respectively. The coolest waters were in the Northern Irish Sea around the Isle of Man $(\mathrm{aDD}=4004)$

316 where whelk grow to the greatest maximum size observed in this study $\left(\mathrm{L}_{\infty}=116.8 \mathrm{~mm} \mathrm{TSL}\right)$. The

317 variation in estimated size-at-age produced by the gompertz model (figure 4) was larger in the Isle of

318 Man sample than in other samples. Intra-site analysis showed that this increased variation resulted from

319 cross-sampling across several distinct whelk populations on the east coast of the Isle of Man, with

320 'Northeast' and 'East' sites exhibiting significantly different size structures (see Emmerson, et al.,

321 2018). Low sample size for each site prevented separate analysis of statoliths, highlighting the need for

322 spatially specific sampling at local scales, particularly where localised hydrographic and bathymetric

323 variations affect ambient temperature. Significant differences in growth rate between the northeast area

324 of the Isle of Man and the rest of the territorial sea have also been observed in king scallop populations

325 (Dignan, et al., 2014).

327 Other Gompertz growth coefficients $\left(K_{G}\right.$ and $\left.T_{i}\right)$, i.e. the maximum rate of growth and the point of 328 growth rate inflection, showed marginally non-significant linear relationships with aDD $(p=0.07$ for 329 both coefficients). Increased sampling may change the outcome of these analyses, since visual 330 interpretation of the data (figure 6) shows that there is a trend between aDD and both $K_{G}$ and $T_{i}$. The 331 maximum rate of growth $\left(K_{G}\right)$ showed a strong positive correlative trend with aDD, where populations 332 of whelk in Swansea Bay and Carmarthen Bay (South Wales) had the highest coefficient value, 0.98 333 and 1.04 respectively. These values indicate that the warmer sea bottom temperature, whilst limiting 334 the maximum potential size of whelk, also accelerates the rate of growth of individual during early life335 stages. The slowest growth-rate coefficient value was observed in cooler waters around the Isle of Man $336\left(K_{G}=0.44\right)$. The point at which this gompertz growth rate begins to decrease from the maximum $\left(T_{i}\right)$ 337 showed a negative correlative trend with aDD. Growth of whelks in warm waters such as Swansea Bay 
338 begins to decrease at age 0.94 years, whereas in the Isle of Man growth rate begins to decrease at 2.81

339 years.

341 Whelk populations found at higher latitudes in the northern hemisphere generally have a larger 342 maximum body size than those living further south (Hollyman, 2017a), despite initial slower growth 343 rates. This is a common pattern among many ectotherms, such as the scallop Pecten maximus 344 (Chauvaud, et al., 2012). Chauvaud et al. (2012) observed that low annual growth rates in northern 345 populations are not due to low daily growth rates, but rather a fewer number of days (thermal window) 346 within which scallop growth could occur, which was also hypothesised in the case of whelk by 347 Hollyman (2017a). Chauvaud et al. (2012) also showed that, "despite initial lower annual growth 348 performance ... differences in asymptotic size $\left(\mathrm{L}_{\infty}\right)$ as a function of latitude resulted from persistent 349 annual growth performances in the north and sharp declines in the south". Classical growth models 350 have failed to capture this dynamic in long-lived ectotherms that have thermally constrained growing 351 seasons (Chauvaud, et al., 2012), such as whelk. The growth observed in the data for whelk in the Irish 352 Sea point to Bergmans rule, "a general trend of animal sizes to increase with latitude" (Blackburn, et 353 al., 1999). Clearly, higher ambient temperature drives rapid growth in whelk in the early life-stages of 354 the species with larger time-windows for growth, but they reach a smaller asymptotic maximum size 355 earlier in life. These patterns are captured in the behaviour of the gompertz curve, which explained 356 growth in Buccinum with a greater $\mathrm{R}^{2}$ and goodness-of-fit values than other analyses (Hollyman, et al., 357 2018). We also hypothesise that as well as being temperature drive, the time-window for growth 358 decreases with age in whelks, which is consistent with the notion that as they mature there is a trade-off 359 between growth and reproduction or defence, resulting in a decrease in the length of growing season 360 with age (Stearns, 1992; Lankford, et al., 2001). Chauvaud et al. (2012) were able to demonstrate with 361 scallops that the decrease in the length of growing seasons with age is more rapid at lower latitudes, a 362 hypothesis that may also be reflected in the data presented here.

364 It is important that data and models explaining species life-history are incorporated into fisheries 365 management where possible. Whelk fisheries in both the Isle of Man and Wales are considered "data 366 poor" though they are managed primarily with an MLS informed by size-at-maturity studies (Haig et 367 al., 2015; Emmerson et al., 2018). Viewing the analyses in this study in the context of other work on 
368 whelk in Welsh waters and the Isle of Man (see Haig et al., 2015; Hollyman, 2017a; Emmerson et al.,

369 2018) suggests that, on average, populations reach functional maturity $\left(\mathrm{L}_{50}\right)$ by age 4 . It may therefore 370 be possible to also estimate reproductive characteristics, upon which MLS is ideally referenced, using 371 solely temperature data if the temperature growth parameters are further investigated and the 372 relationship is substantiated with additional data. Broadly speaking, management of whelk fisheries in 373 the Northeast Atlantic should follow a latitudinal pattern of increasing MLS with latitude. The EU 374 minimum conservation reference size (MCRS) of $45 \mathrm{~mm}$ TSL may well be sufficient to protect 375 spawning stock according to $\mathrm{L}_{50}$ estimates in parts of the English Channel (McIntyre, et al., 2015), but 376 it is insufficient in the Irish Sea where $\mathrm{L}_{50}$ has been shown to be up to $75 \mathrm{~mm}$ TSL (Emmerson, et al., 377 2018). As whelk fisheries continue to expand throughout the British Isles, it is essential that 378 management is both evidence-based and regionalised.

380 Within the context of the Irish Sea region, a linear relationship sufficiently explains the variation in the 381 SBT- $\mathrm{L}_{\infty}$ relationship $(\mathrm{p}=0.03)$ and provides good cause to suspect the relationship can be explain other 382 growth coefficient factors $\left(K_{G}\right.$ and $\left.T_{i}\right)$. However temperature in the Irish Sea varies over a relatively 383 narrow range compared to the temperatures experienced by whelk over the full geographical extent of 384 the species. Whelk are highly eurythmic and have been reported to survive in temperatures from below $3850{ }^{\circ} \mathrm{C}$ to above $22{ }^{\circ} \mathrm{C}$ (Smith, et al., 2013). We hypothesize a non-linear relationship between 386 temperature and $\mathrm{L}_{\infty}$ of this species over its geographical distribution with asymptotic limits to the size 387 of whelk in populations as average SBT approaches the lower and upper critical thermal limits (Figure 388 8). Indeed, anecdotal evidence supports this hypothesis, such that preliminary observations in the 389 Orkney Islands (northern Scotland) show $\mathrm{TSL}_{\infty} \approx 140 \mathrm{~mm}$ at $\mathrm{aDD}=3,465$ (M. Coleman, unpublished 390 data). A broad-range study to explore this relationship would also reveal whether populations of whelk 391 exhibit ecotypical characteristics, where subpopulations may have undergone genotypic adaptions to 392 specific environmental conditions that affect life-history traits such as growth. It is possible that, 393 following successful validation of the DD growth relationship in further studies by combining both 394 laboratory and field-based methodologies, the growth rate of this species can be modelled throughout 395 its distribution based solely on open source satellite-based temperature data. However, more work is 396 required to validate the relationship in the first instance. 
$<$ Figure 8>

Figure 8. A hypothetical illustration of the relationship between degree days $\left({ }^{\circ} \mathrm{C}\right)$ and $\mathrm{L}_{\infty}$ for the common whelk (Buccinum undatum).

It is anticipated that refinement of the aDD variable according to critical thermal limits of the species, which are currently unknown, may result in the analytical models showing a statistical significance in the temperature $\sim$ growth relationship for all parameters. This study analysed the growth parameters of whelk against a single aDD value (the average annual DD for the period 2010-2016), however further investigations looking into the parameters that define DD over time (the maximum rate of increase in DD (DDr), the point of inflection in DD (DDi) during the year) are warranted. That is to say, the mechanistic effect of temperature on whelk may be such that aDD, which calculates the average annual thermal input into the environment, has limited explanatory power. Instead, for example, it may be that it is the rate of thermal input within specific season that provides greater statistical power in explaining growth. In order to precisely analyse these hypotheses and to observe localised hydrographic anomalies, temperature data would have to be generated from direct observations using temperature loggers fixed to the seabed as opposed to the low resolution satellite data used in this study. Another method that may further validate the temperature $\sim$ growth relationship would be laboratory-based studies, which control the temperature of the environment as a fixed variable in order to fully understand the specific thresholds that drive and limit the energetic input into shell growth, as well as the species specific thermal preferendum. In contrast to this study, which conducted a post-hoc analysis using available temperature data, controlling for temperature as part of the experimental design would add greater certainty to the relationship. The importance of understanding the environmental context of sampling locations (fishing grounds) has been highlighted previously (Hollyman, et al., 2018). Indeed, any specific thermal preferendum that exists to encourage energetic investment in shell growth for this species would necessitate an experimental design that controlled for specific thermal parameters as well as other confounding variables (e.g. food availability (Nasution \& Roberts, 2004), predatory pressure and aquatic chemistry). Given the opportunistic post-hoc nature of this study, and that the analysis was performed on aggregated one-dimensional temperature data (aDD), it is encouraging that a clear and significant relationship is observed (figure 7). 
428 This study presents the first comparison of growth rates of sampled whelk populations throughout the 429 latitudinal extent of a fisheries management region (ICES VIIa), using data modelled from statolith 430 analysis. A linear trend was observed between SBT, expressed as aDD, and $\mathrm{L}_{\infty}$ whereby warmer waters 431 limited maximum shell size. When extrapolated throughout the entire geographical extent of ICES 432 VIIa, the data broadly mirrors the reported parameters in other studies. Further verification of the

433 temperature $\sim$ growth relationship for this species is required, combining both broad geographical 434 collaborations and controlled laboratory methodologies. Validating this relationship may lead to broad435 scale extrapolations throughout the species distribution, which would provide an increadibly valuable 436 and timely resource to fisheries managers who would otherwise depend on dedicated sampling studies 437 to understand the life-history parameters of whelk stocks, which are currently recognised as being data438 poor and potentially over exploited.

\section{Acknowledgments}

441 This project would not have been possible without the help of the Welsh Fisherman's Association 442 (WFA), the Manx Fish Producers Organisation (MFPO) and other members of the fishing industry that 443 voluntarily provided biological samples. The project was funded in Wales by the Welsh Government 444 and in the Isle of Man by the Isle of Man Government's Department for Environment, Food \& 445 Agriculture (DEFA). We would also like to extend our gratitude to all those who responsible for 446 directing and ovseeing projects associated with this research, including Michel Kaiser, Chris 447 Richardson and Charlotte Colvin. We would also like to thank Claire Lambden for assistence in 448 extracting statoliths from samples. 


\section{References}

Angilletta Jr., M. J., Niewiarowski, P. H. \& Navas, C. A., 2002. The evolution of thermal physiology in ectotherms. Journal of Thermal Biology, Volume 27, pp. 249-268.

Barroso, C. M., Nunes, M., Richardson, C. A. \& Moreira, M. H., 2005. The gastropod statolith: a tool for determining the age of Nassarius reticulatus. Marine Biology, Volume 146, pp. 1139-1144.

Bell, M. C. \& Walker, P., 1998. Size at maturity in common whelks (Buccinum undatum, L.) in

England and Wales. ICES Document CM1998, CC(9), pp. 1-24.

Bennett, A. F., 1980. The thermal dependence of lizard behaviour. Animal Behaviour, Volume 28, pp. 752-762.

Blackburn, T. M., Gaston, K. J. \& Loder, N., 1999. Geographic gradients in body sizes: a clarification of Bergman's rule.. Diversity and Distributions, Volume 165-174, p. 5.

Borsetti, S. et al., 2018. Spatial variation in life history characteristics of waved whelk (Buccinum undatum, L.) on the U.S Mid-Atlantic continental shelf. Fisheries Research, Volume 198, pp. 129-137.

Chatzinikolaou, E. \& Richardson, C. A., 2007. Evaluating growth and age of the netted whelk Nassarius reticulatus (Gastropoda: Nassariidae) using statolith growth rings. Marine Ecology Progress Series, Volume 342, pp. 163-176.

Chauvaud, L. et al., 2012. Variation in Size and Growth of the Great Scallop (Pecten maximus) along a Latitudinal Gradient. PLoS One, 7(5), p. e37717.

Chezik, K. A., Lester, N. P. \& Venturelli, P. A., 2014. Fish growth and degree-days I: selecting a base temperature for a within-population study. Canadian Journal of Fisheries and Aquaculture Science, Volume 71, pp. 47-55.

Chezik, K. A., Lester, N. P. \& Venturelli, P. A., 2015. Fish growth and degree-days II: selecting a base temperature for an among-population study. Canadian Journal of Fisheries and Aquatic Science, Volume 71, pp. 1303-1311.

Dakin, W., 1912. Memoirs on Typical British Marine Plants and Animals: Buccinum (the Whelk). Liverpool Mrine Biology Commitee Memoirs, Volume 20, p. 123.

Dignan, S., Bloor, I. S., Murray, L. G. \& Kaiser, M. J., 2014. Management evaluation report of a limited king scallop (Pecten maximus) fishery within Ramsey Bay fisheries management zone, Bangor University: Fisheries and Conservation Science Report No. 34.

Emmerson, J. A., Haig, J. A., Bloor, I. S. \& Kaiser, M. J., 2018. The complexities and challenges of conserving common whelk (Buccinum undatum, L.) fishery resources: Spatio-temporal study of variable population demographics within an environmental context. Fisheries Research, Volume 204, pp. $125-136$.

Fahy, E. et al., 2005. Fishery-associated changes in the whelk Buccinum undatum stock in the southwest Irish Sea, 1995-2003, Dublin: Irish Fisheries Investigations Number 15.

Fahy, E., Masterson, E., Swords, D. \& Forrest, N., 2000. A second Assessment of the whelk fishery

488 Buccinum undatum in the Southwest Irish Sea with Particular Reference to its History of Management 489 by Size Limit, Dublin: Marine Institute.

490 FAO, 2017. Species Fact Sheets: Buccinum undatum. [Online]

491 Available at: http://www.fao.org/fishery/species/2659/en

$492 \quad$ [Accessed 2701 2017].

493 Ferreira, T. \& Rasband, W., 2012. ImageJ User Guide 1.46r, s.1.: ImageJ/Fiji. 
Goodwin, D. H., Flessa, K. W., Schone, B. R. \& Dettman, D. L., 2001. Cross-calibration of daily growth increments, stable isotope variation, and temperature in the Gulf of California bivalve mollusc Chione cortzi: Implications of paleoenvironmental analysis. Palaios, Volume 16, pp. 387-398.

Haig, J. A. et al., 2015. Temporal and spatial variation in size at maturity of the common whelk (Buccinum undatum). ICES Journal of Marine Science, 72(9), pp. 2707-2719.

Heath, M. R. et al., 2012. Review of climate change impacts on marine fish and shellfish around the UK and Ireland. Aquatic Conservation: Marine and Freshwater Ecosystems, Volume 22, pp. 337-367.

Hilborn, R. \& Walters, C. J., 1992. Quantitative Fisheries Stock Assessment: Choices, Dynamics and Uncertainty.. New York: Chapman \& Hall.

Hollowed, A. B. et al., 2013. Projected impacts of climate change on marine fish and fisheries. ICES Journal of Marine Science, 70(5), pp. 1023-1037.

Hollyman, P. R., 2017a. Age, growth and reproductive assessment of the whelk, Buccinum undatum, in coastal shelf seas. PhD Thesis, Bangor University, School of Ocean Sciences.

Hollyman, P. R. et al., 2017b. Micro-scale geochemical and crystallographic analysis of Buccinum undatum statoliths reveal annual periodicity of visible growth rings. Chemical Geology.

Hollyman, P. R. et al., 2018. Age and growth rate estimations of the commercially fished gastropod Buccinum undatum.. ICES Journal of Marine Science.

Hollyman, P. R. et al., 2018a. Statoliths of the whelk Buccinum undatum: a novel age determination tool. Marine Ecology Progress Series, Volume 598, pp. 261-272.

Huey, R. B. \& Stevenson, R. D., 1979. Integrating thermal physiology and ecology of ectotherms: a discussion of approaches. American Zoologist, Volume 19, pp. 357-366.

Kideys, A. E., 1996. Determination of age and growth of Buccinum undatum L. (Gastropoda) off Douglas, Isle of Man.. Helgol Meeresunters, Volume 50, pp. 353-368.

Lankford, T. E., Billerbeck, J. M. \& Conover, D. O., 2001. Evolution of intrinsic growth and energy acquisition rates. II. Trade-offs with vulnerability to predation in Menidia menidia. Evolution, Volume 55, pp. 1873-1881.

Laptikhovsky, V. et al., 2016. A novel approach for estimation of the natural mortality of the common whelk, Buccinum undatum (L.) and role of hermit crabs in its shell turnover. Fisheries Research, Volume 183, pp. 146-154.

Lawrence, S., Motova, A. \& Russell, J., 2017. Quay Issues: Fleet Economic Performance Dataset 2008-16, Edinburgh, UK: Seafish Economics.

Lonsdale, D. J. \& Levinton, J. S., 1985. Latitudinal differentiation in copepod growth: an adaption to temperature. Ecology, Volume 66, pp. 1397-1407.

Lonsdale, D. J. \& Levinton, J. S., 1989. Energy budgets of latitudinally separated Scottolana canadenis (Copepoda: Harpacticoida). Limnology and Oceanography, Volume 34, pp. 324-331.

McIntyre, R., Lawler, A. \& Masefield, R., 2015. Size of maturity of the common whelk, Buccinum undatum: Is the minimum landing size in England too low?. Fisheries Research, Volume 162, pp. 5357.

Mercier, A. \& Hamel, J. F., 2008. Nature and role of newly described symbiotic associations between sea anemone and gastropods at bathayal depths in the NW Atlantic. Journal of Experimental Marine Biology and Ecology, Volume 358, pp. 57-69. 

upon-Tyne: Marine Management Organisation.

Nasution, S. \& Roberts, D., 2004. Laboratory trials on the effects of different diets on growth and survival of the common whelk, Buccinum undatum L. 1758, as a candidate species for aquaculture. Aquaculture International, Volume 12, pp. 509-521.

540 Navaro, E. \& Iglesias, J. I., 1995. Energetics of reproduction related to environmental variability in 541 bivalve molluscs. Haliotis, Volume 24, pp. 43-55.

Neuheimer, A. B. \& Taggart, C. T., 2007. The growing degree-day and fish size-at-age: the overlooked metric. Canadian Journal of Fisheries and Aquaculture Science, 64(2), pp. 375-385.

544 Nicholson, G. J. \& Evans, S. M., 1997. Anthropogenic impacts on the stocks of the common whelk

545 Buccinum undatum (L.). Marine Environmental Research, Volume 44, pp. 305-314.

Peck, L. S. et al., 2009. Animal temperature limits and ecological relevence: effects of size, activity and rates of change. Functional Ecology, 23(2), pp. 248-256.

Pörtner, H. O., Peck, L. S. \& Somero, G. N., 2007. Thermal limits and adaption in marine Antasctic 362 , pp. 2233-2258.

R Core Team, 2017. R: A language and environment for statistical computing. $R$ Foundation for

552 Statistical, Vienna, Austria.

Richardson, C. A., Saurel, C., Barroso, C. M. \& Thain, J., 2005. Evaluation of the age of the red whelk Neptuna antiqua using statoliths, opercula and elemnt ratios in the shell. Journal of Experimental Marine Biology and Ecology, Volume 325, pp. 55-64.

Rueden, C. T., Schindelin, J. \& Hiner, M. C., 2017. ImageJ2: ImageJ for the next generation of scientific image data. BMC Bioinformatics, 18(529).

Santarelli, L. \& Gros, P., 1985. Age and growth of the whelk Buccinum undatum L. (Gastropoda:

559 Prosobranchia) using stable isotopes of the shell and operculum striae.. Oceanologica Acta, Volume 8, 560 pp. 221-229.

561 SEAFISH Economics, 2018. Seafish fleet economic performance dataset 2007-2017, Edinburgh, UK: 562 Seafish Economics.

563 Sharpe, P. J. \& DeMichele, D. W., 1977. Reaction kinetics of poikilotherm development. Journal of 564 Theoretical Biology, 64(4), pp. 649-670.

565 Shelmerdine, R. L., Adamson, J., Laurenson, C. H. \& Leslie, B., 2007. Size variation of the common whelk, Buccinum undatum, over large and small spatial scales: Potential implications for micromanagement within the fishery. Fisheries Research, Volume 86, pp. 201-206.

568 Shrives, J. P., Pickup, S. E. \& Morel, G. M., 2015. Whelk (Buccinum undatum L.) stocks around the Island of Jersey, Channel Islands: Reassessment and implications for sustainable management.

570 Fisheries Research, Volume 167, pp. 236-242.

571 Smith, K. E., Thatje, S. \& Hauton, C., 2013. Thermal tolerance during early ontogeny in the common 572 whelk Buccinum undatum ( Linnaeus 1785 ): Bioenergetics, nurse egg partitioning and developmental 573 success. Journal of Sea Research, Volume 79, pp. 32-39.

574 Smith, K. E., Thatje, S. \& Hauton, C., 2013. Thermal tolerance during early ontogeny in the common 575 whelk Buccinum undatum (Linnaeus 1785): Bioenergetics, nurse egg partitioning and developmental success. Journal of Sea Research, Volume 79, pp. 32-39. 
577 Stearns, S. C., 1992. The evolution of life histories. Oxford: Oxford University Press.

578 Tjørve, K. M. \& Tjørve, E., 2017. The use of Gompertz models in growth analyses, and new

579 Gompertz-model approach: An addition to the Unified-Richards family. PLOS ONE, 12(6), pp. 1-17.

580 Valentinsson, D., 2002. Reproductive cycle and maternal effects on offspring size and number in the 581 neogastropod Buccinum undatum. Marine Biology, 140(6), pp. 1139-1147.

582 Werner, Y. L., 1976. Optimal temperatures for inner-ear performance in gekkonis lizards. Journal of 583 Experimental Zoology, Volume 195, pp. 319-352.

584 Young, J. S., Peck, L. S. \& Matheson, T., 2006. The effects of temperature on walking in temperatre 585 and Arctic crustaceans. Polar Biology, 29(11), pp. 978-987. 
Table 1. Summary of results from growth models for each location, including parameter estimates for model coefficients, where $L_{\infty}$ is estimated maximum shell size, $k_{G}$ is the growth-rate coefficient and $T_{i}$ is the point of inflection in the model curve. Parameter statistical significance shown by $p$ value $(* * *=<0.001)$.

\begin{tabular}{|c|c|c|c|c|c|}
\hline Model & Param & Est & S.E & t-value & sig. \\
\hline \multirow{3}{*}{ Isle of Man } & $\mathrm{L}_{\infty}$ & 116.8 & 4.77 & 24.5 & $* * *$ \\
\hline & $k_{\mathrm{G}}$ & 0.44 & 0.02 & 17.7 & $* * *$ \\
\hline & $T_{i}$ & 2.81 & 0.11 & 24.5 & $* * *$ \\
\hline \multirow{3}{*}{ Anglesey } & $\mathrm{L}_{\infty}$ & 90.9 & 1.45 & 1.162 .6 & $* * *$ \\
\hline & $k_{\mathrm{G}}$ & 0.72 & 0.03 & 22.2 & $* * *$ \\
\hline & $T_{i}$ & 1.47 & 0.03 & 44.2 & $* * *$ \\
\hline \multirow{3}{*}{ Nefyn } & $\mathrm{L}_{\infty}$ & 89.6 & 1.19 & 74.9 & $* * *$ \\
\hline & $k_{\mathrm{G}}$ & 0.71 & 0.03 & 24.2 & $* * *$ \\
\hline & $T_{i}$ & 1.59 & 0.03 & 55.9 & $* * *$ \\
\hline \multirow{3}{*}{ Bardsey } & $\mathrm{L}_{\infty}$ & 91.5 & 0.99 & 92.0 & *** \\
\hline & $k_{\mathrm{G}}$ & 0.74 & 0.03 & 26.2 & $* * *$ \\
\hline & $T_{i}$ & 1.96 & 0.04 & 54.6 & $* * *$ \\
\hline \multirow{3}{*}{$\begin{array}{l}\text { Carmarthen } \\
\text { Bay }\end{array}$} & $\mathrm{L}_{\infty}$ & 81.9 & 1.49 & 54.9 & $* * *$ \\
\hline & $k_{\mathrm{G}}$ & 1.04 & 0.06 & 16.8 & $* * *$ \\
\hline & $T_{i}$ & 1.14 & 0.04 & 30.3 & *** \\
\hline \multirow{3}{*}{ Swansea } & $\mathrm{L}_{\infty}$ & 59.9 & 1.77 & 33.7 & $* * *$ \\
\hline & $k_{\mathrm{G}}$ & 0.98 & 0.06 & 11.1 & *** \\
\hline & $T_{i}$ & 0.94 & 0.08 & 13.5 & $* * *$ \\
\hline
\end{tabular}




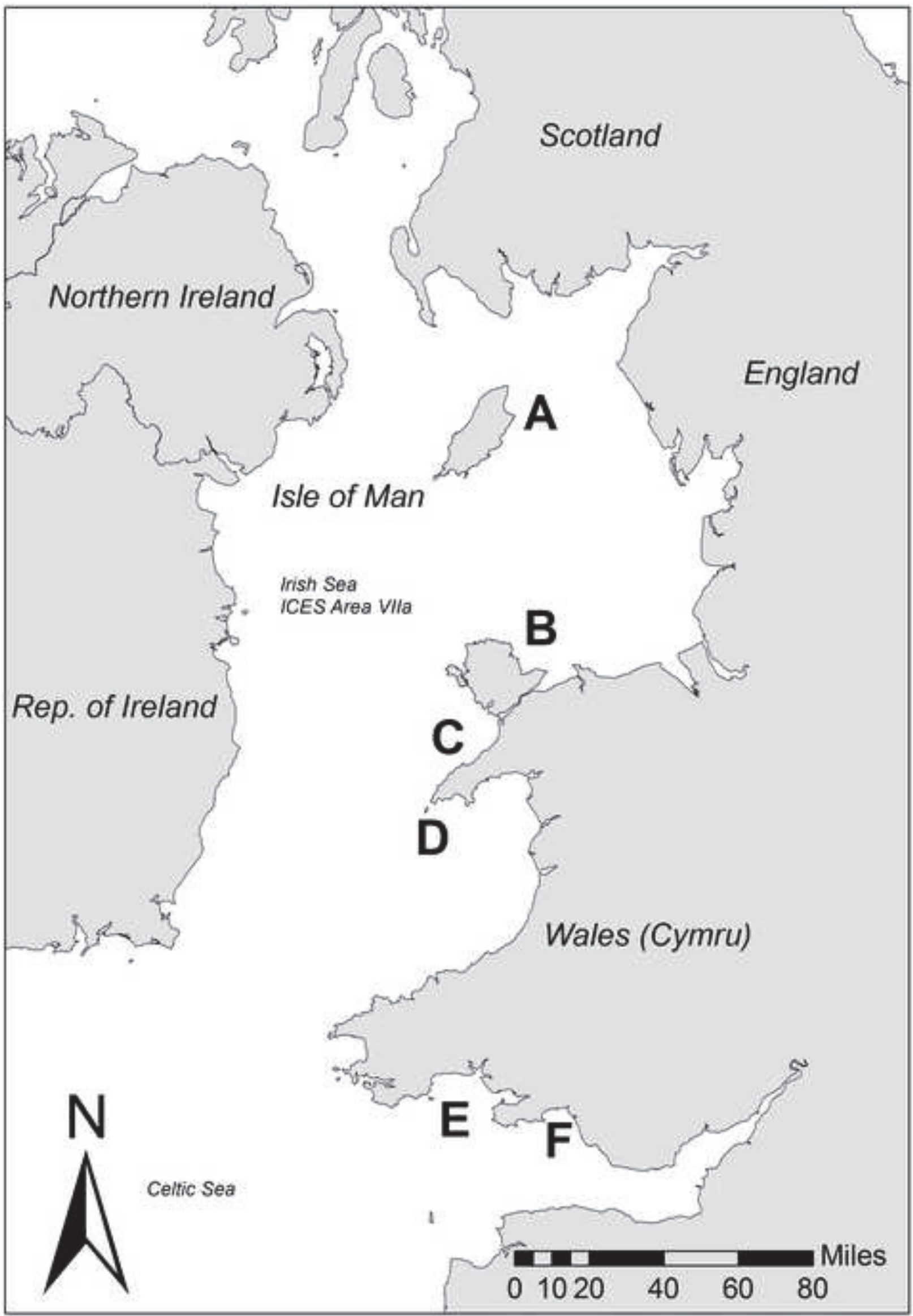




\section{Figure 2}

Click here to download high resolution image

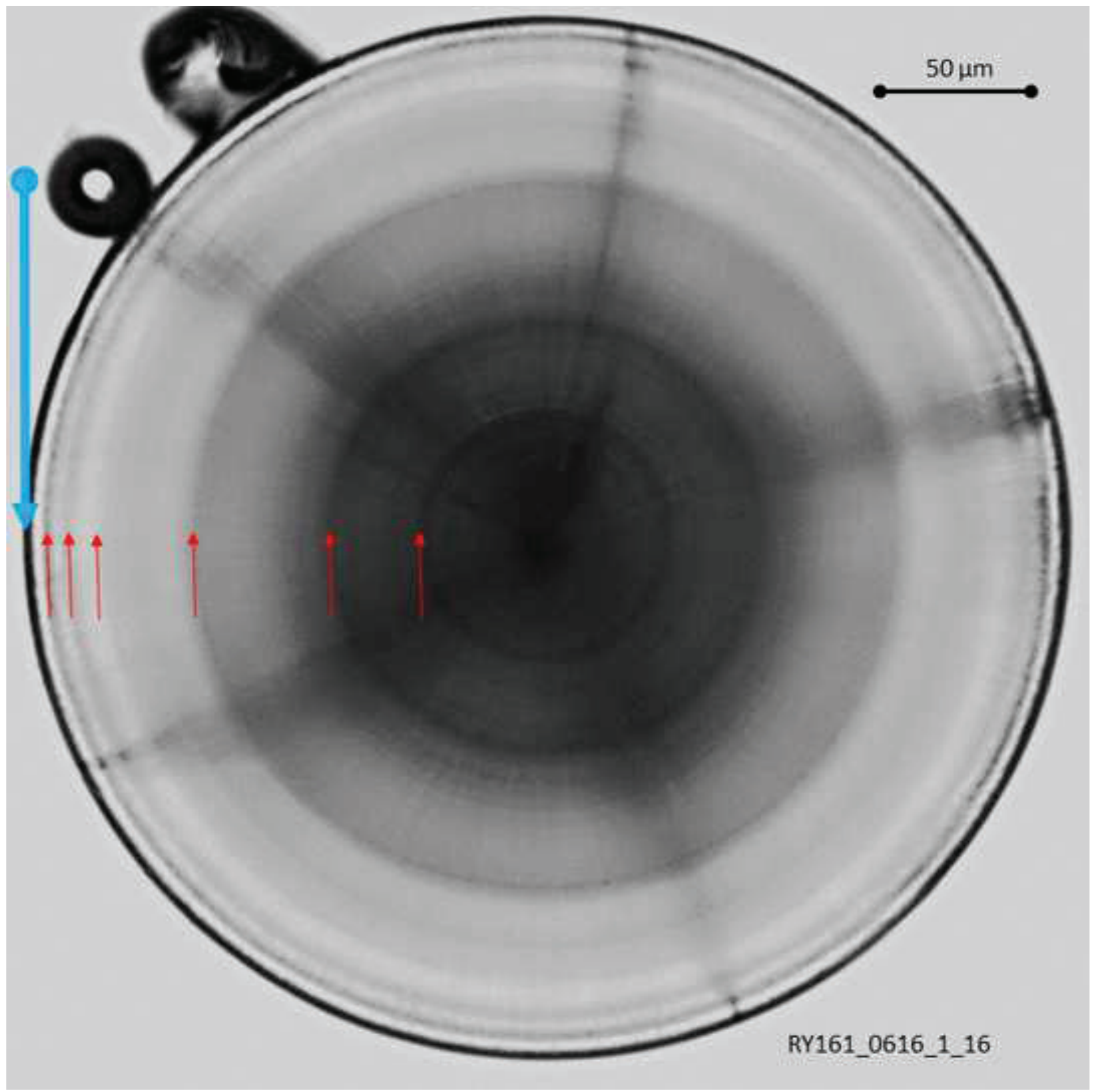



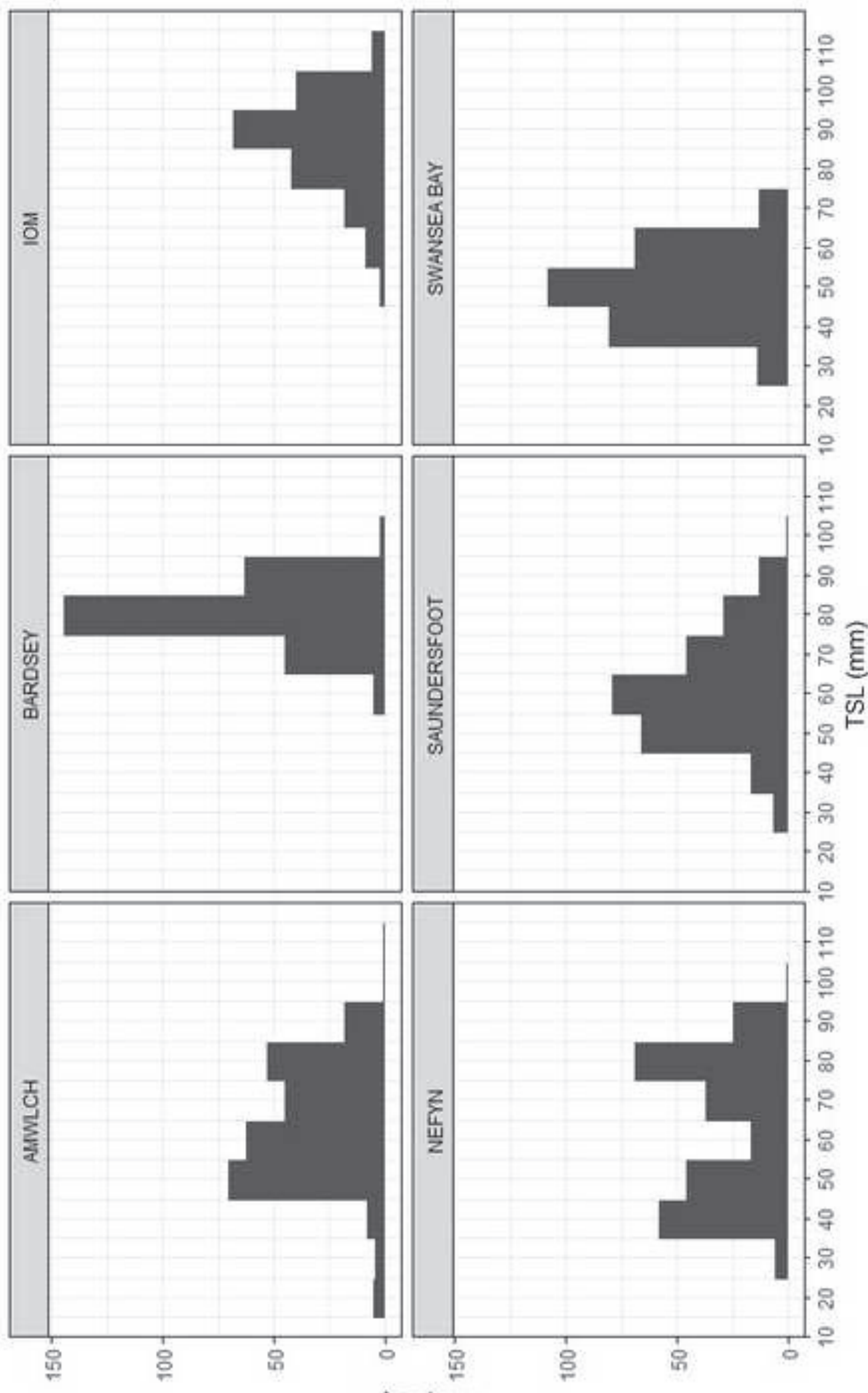

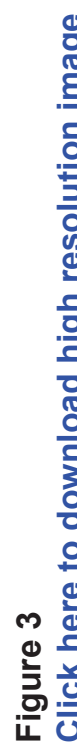




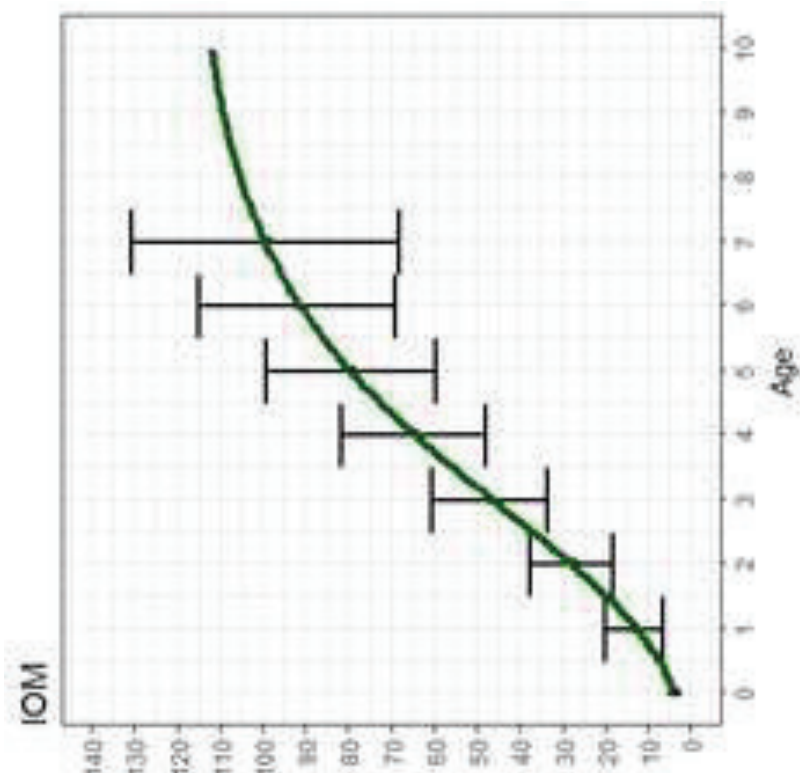

(แแ) $7 \$ 1$

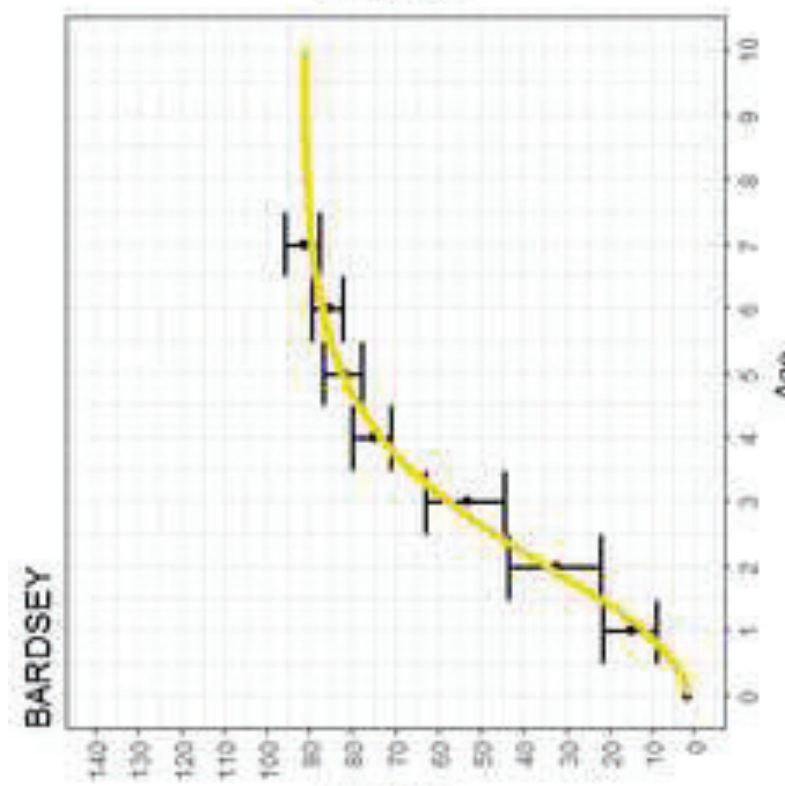

(uL) 791

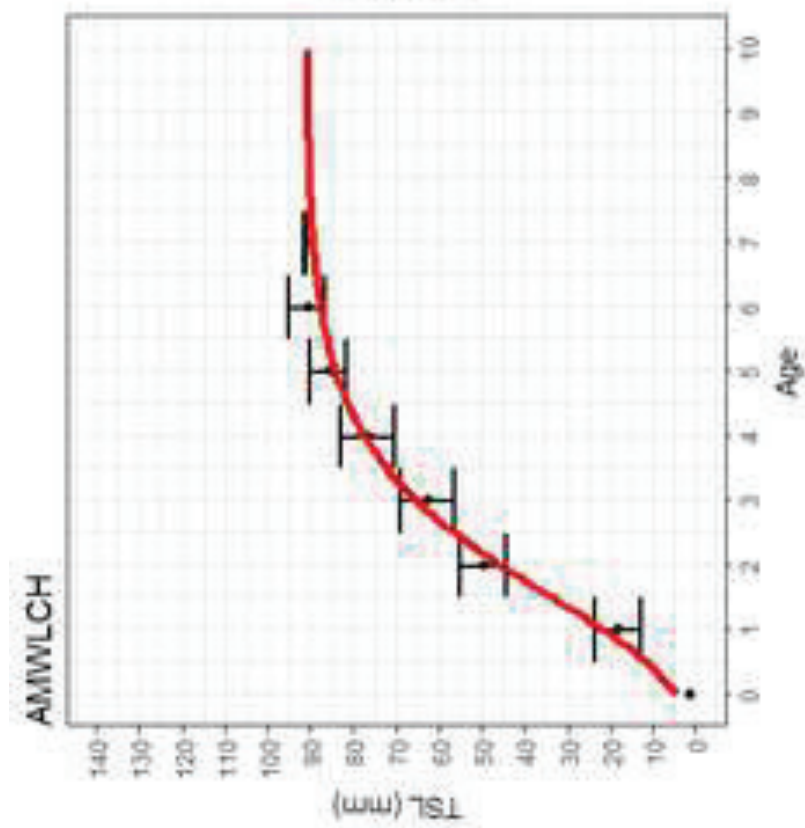

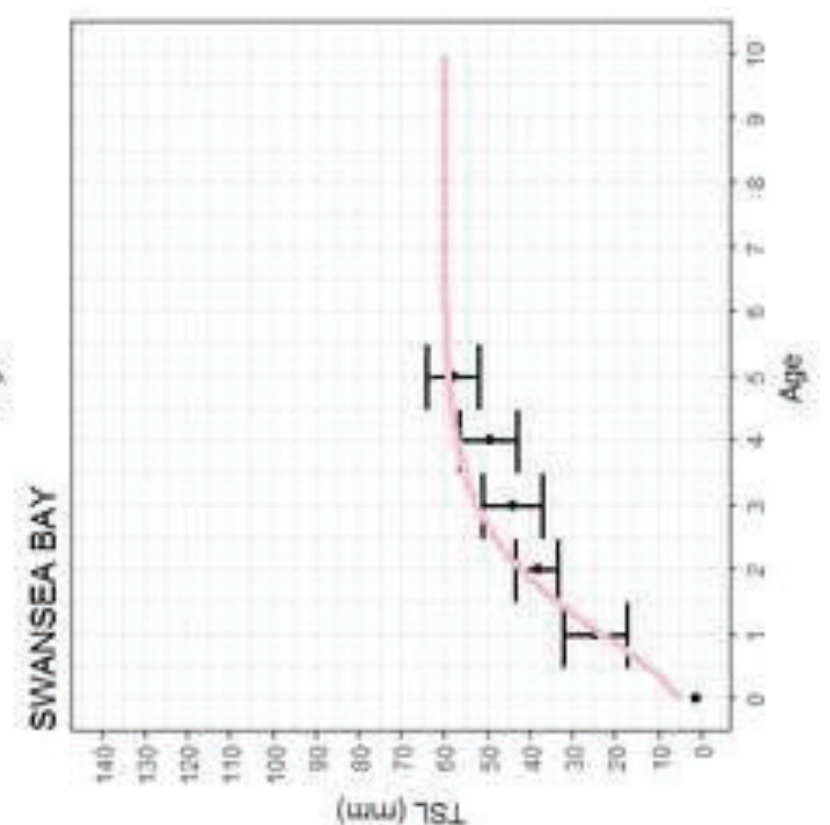

(แนن) $78 \perp$

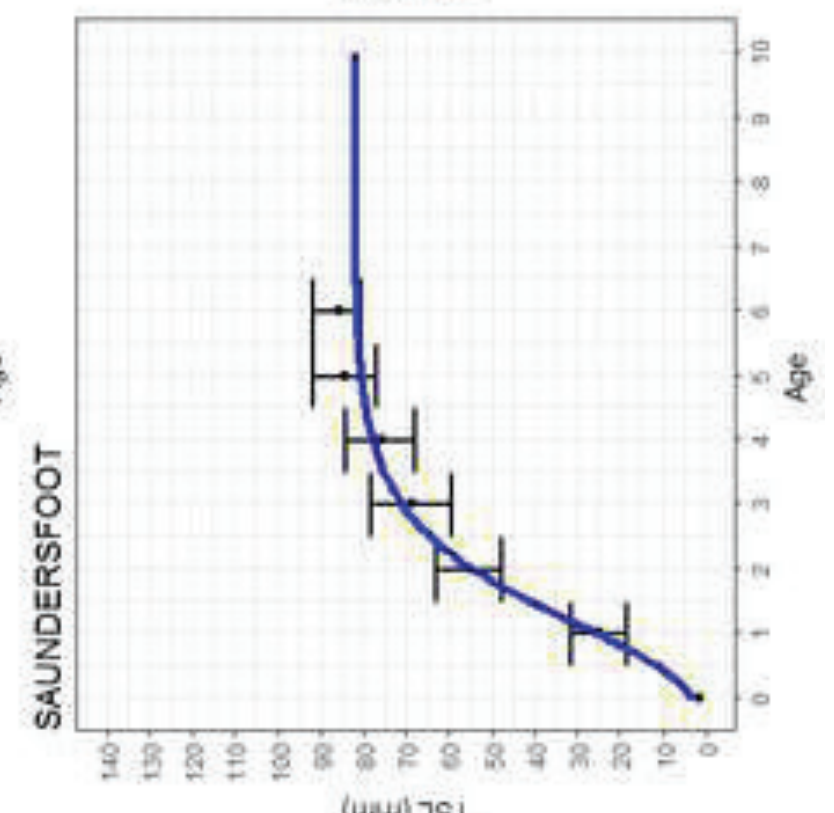

(unv) 791

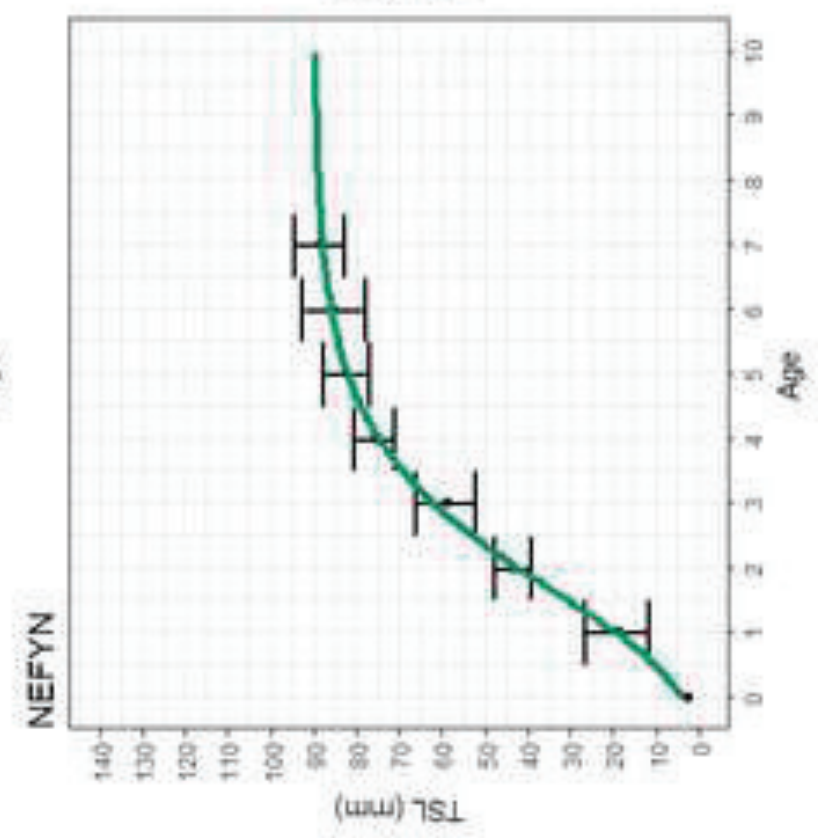



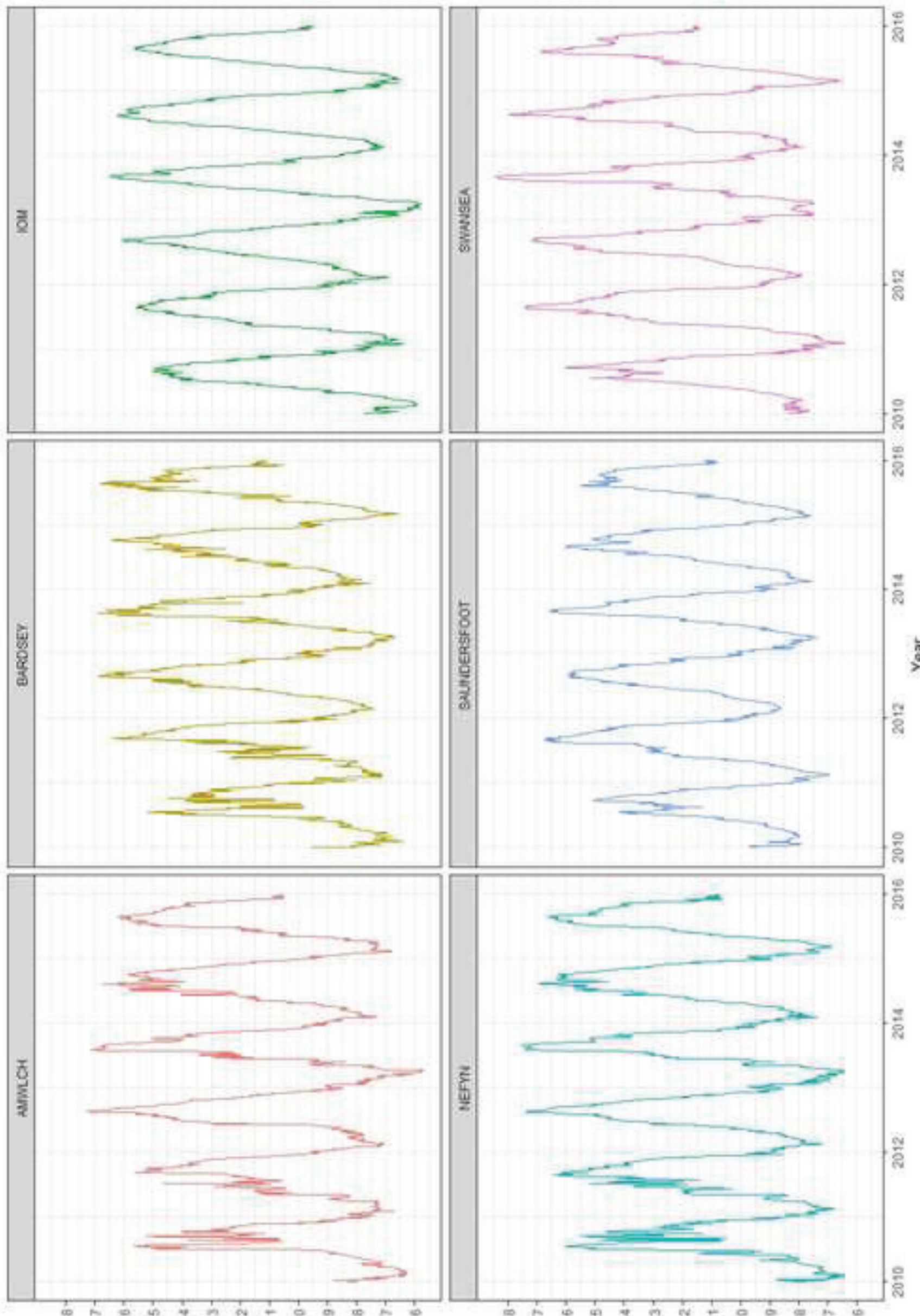

氙

$\frac{2}{8}$

ํํํ

.

in . 

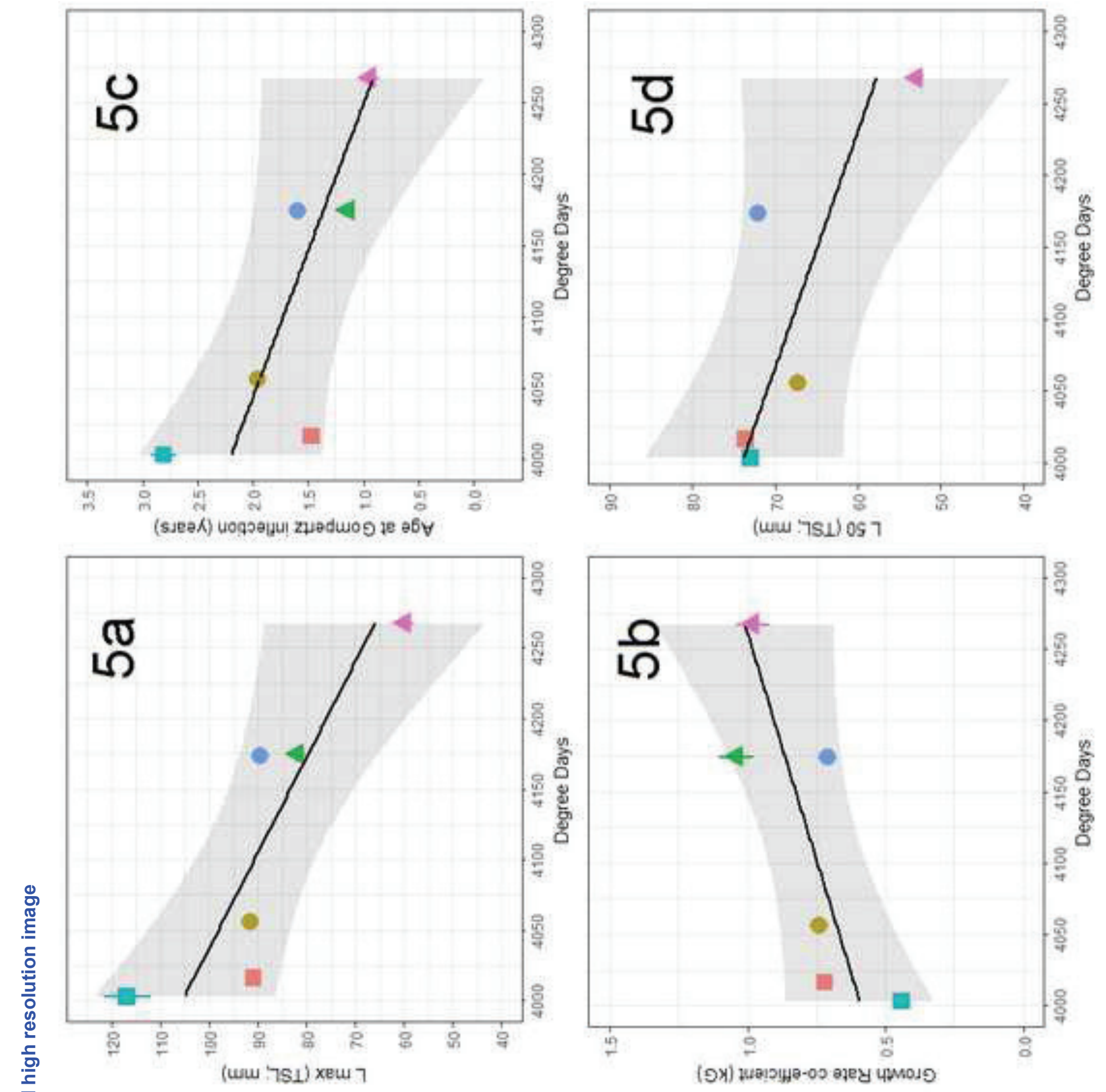
Click here to download high resolution image

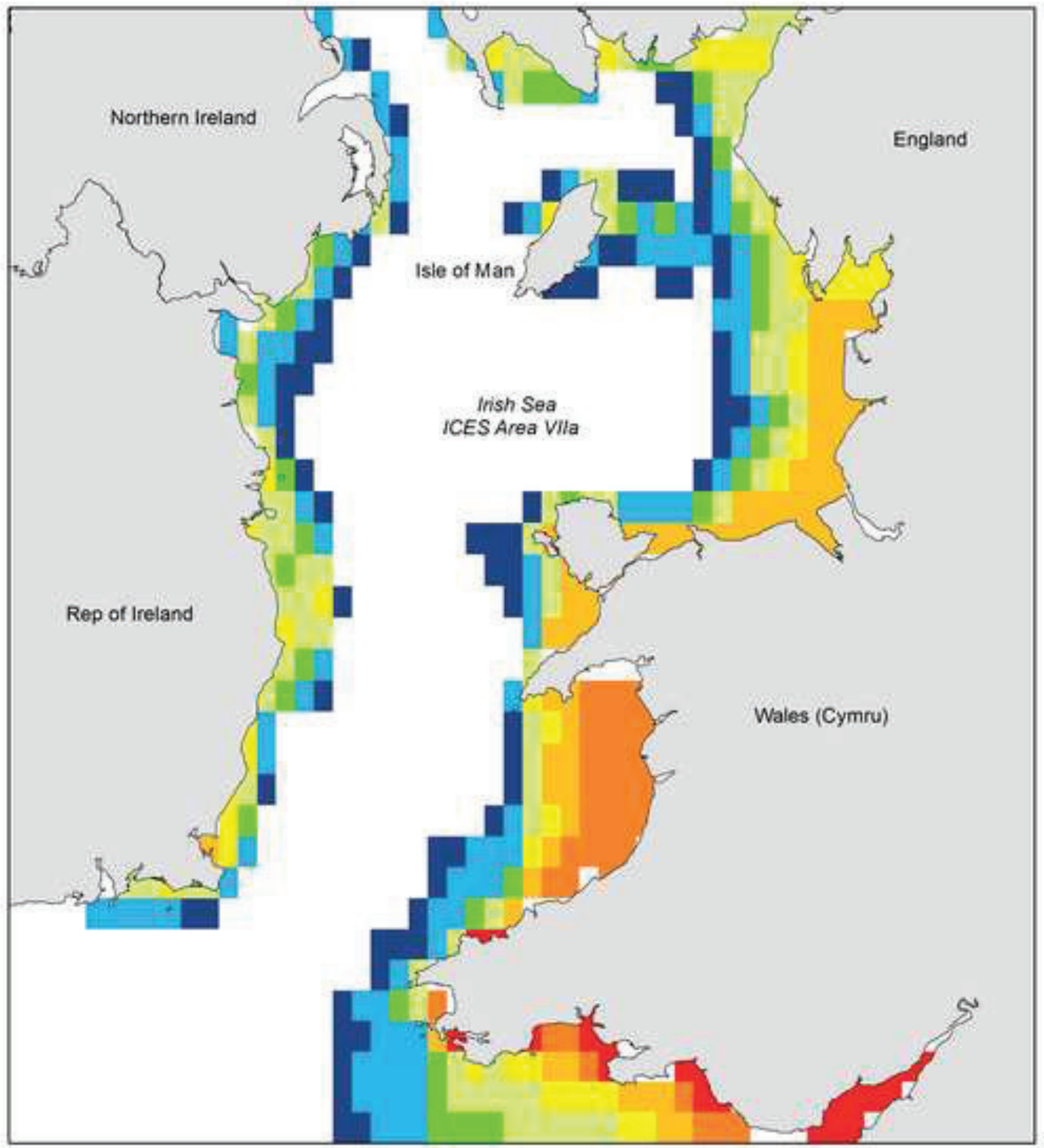

Legend

United Kingdom Republic of Ireland Isle of Man

\section{Lmax}

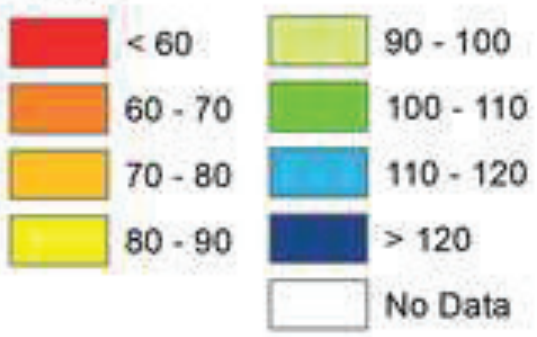




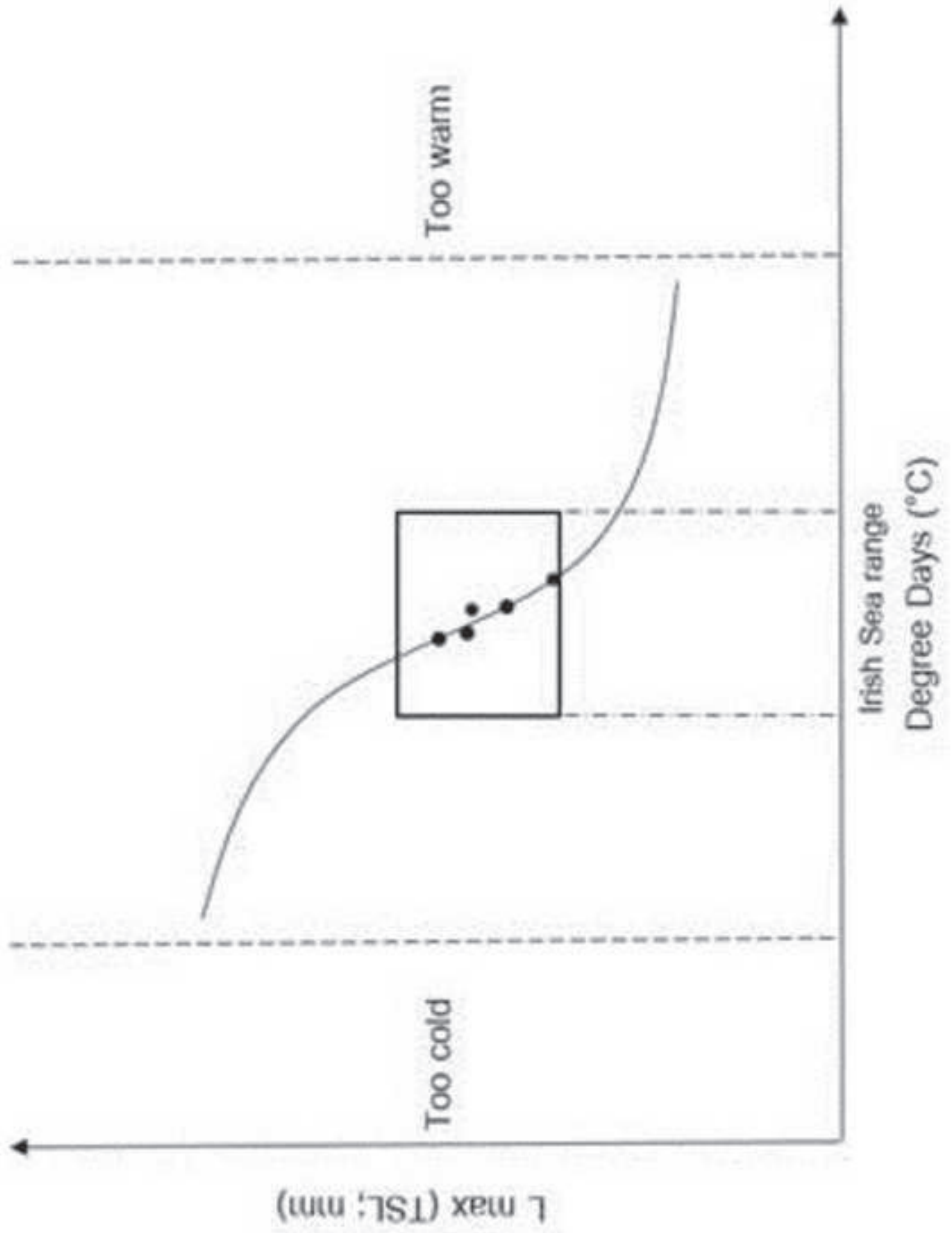

语

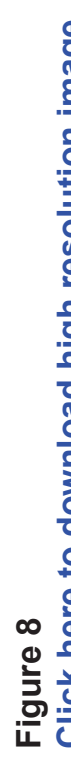

